\title{
Sevoflurane pretreatment prevents lipopolysaccharide (LPS)-induced acute lung injury in rats through up- regulated heme oxygenase-1 (HO-1) expression
}

\author{
Zhaoshuang Ping*, Wu Jiao and Zhang Zhong \\ Department of Critical Care Medicine, Hunan Xiangya Hospital, Central South University, Changsha, China. \\ Accepted 29 June, 2011
}

\begin{abstract}
To observe the effect of sevoflurane pretreatment with different concentrations on lipopolysaccharide (LPS)-induced acute lung injury (ALI) and expression of heme oxygenase-1 (HO-1). Sprague-Dawley (SD) rats were divided into six groups in different sevoflurane pretreatment experiment, Group A (control), Group B (1.5 MAC sevoflurane), Group C (1.5 MAC sevoflurane + LPS), Group D (1.0 MAC sevoflurane + LPS), group E (0.5 MAC sevoflurane + LPS) and Group F (LPS) at random. Besides, SD rats were divided into other six groups in induced HO-1 expression experiment, Group A (control group), Group B (ZnPP), Group C (1.0 MAC sevoflurane), Group D (1.0 MAC sevoflurane + LPS), Group E (ZnPP + 1.0 MAC sevoflurane + LPS) and Group F (LPS). Using traditional method to detect pathological changes, wet/dry ratio (W/D), myeloperoxidase (MPO) and HO-1 activity; detecting the mRNA and protein level of cytokine-induced neutrophil chemoattractant (CINC), and intercellular adhesion molecule-1(ICAM-1) and HO-1 by RT-PCR and Western blot. 1.0 MAC sevoflurane pre-treatment could effectively protect ALI with decreasing pathomorphological scores, MPO activity, W/D and downregulated expression of ICAM-1 and CINC. Furthermore, 1.0 MAC sevoflurane pre-treatment could significantly induced HO-1 expression suggesting sevoflurane may protect ALI from inflammation through inducing abundant HO-1 expression. Sevoflurane pre-treatment may be an effective avenue to alleviate ALI through inducing HO-1 expression.
\end{abstract}

Key words: Sevoflurane, acute lung injury, heme oxygenase-1 (HO-1).

\section{INTRODUCTION}

Initiated by numerous factors, acute lung injury (ALI) is a diffuse heterogeneous lung injury marked by epithelial and endothelial cell perturbation and inflammatory cell influx that leads to hypoxemia, non-cardiogenic pulmonary edema, low lung compliance and widespread capillary leakage (Leikauf et al., 2002; Randhawa and Bellingan, 2007). Activation of neutrophil, release of cytokine-induced neutrophil chemoattractant (CINC) and intercellular adhesion molecule-1(ICAM-1) may play a crucial role in the pathology mechanism of ALI (Bhatia et al., 2000; Lee and Downey, 2001; Coimbra et al., 2006).

Recently, study has indicated that pre-treatment with $0.5 \mathrm{MAC}$ sevoflurane to alveolar epithelial cells for $30 \mathrm{~min}$ could distinctly alleviate lipopolysaccharide (LPS)-

\footnotetext{
*Corresponding author. E-mail: zhaoshuangping@gmail.com.
}

induced inflammation (Suter et al., 2007). Heme oxygenase (HO-1) was increasing expression while the rats cause inhalation ALI by erythrocyte-induced (Pang et al., 2008). However, there was no evidence that pretreatment with sevoflurane could suppress inflammation through inducing HO-1 up-regulated expression. In our work, we designed different experiment groups to depict the protective effect of sevoflurane to $A L I$ and the relationship between sevoflurane and $\mathrm{HO}-1$ in protection process, with hope to give some theoretical supports for clinical application.

\section{MATERIALS AND METHODS}

\section{Animals}

Forty-eight male Sprague-Dawley (SD) rats weighting 220 to $280 \mathrm{~g}$ were provided by animal center of Central South University. The 
animals were housed at a clean, controlled ambient temperature. They were given food and water ad libitum.

\section{Methods}

The effect of sevoflurane pre-treatment with different concentrations on LPS-induced ALI. Forty-eight male SD rats were anesthetized by intraperitoneal injection of $20 \%$ urethane $1 \mathrm{~g} / \mathrm{kg}$ and were tracheostomized to implement mechanical ventilation (with $8 \mathrm{ml} / \mathrm{kg}$ tidal volume and 65 to 70 time/min respiratory frequency). The right femoral artery incubation was used to measure arterial pressure and blood collection, but the left was used for ringer solution and drug injection. After $30 \mathrm{~min}$, these rats were randomly divided into six groups $(n=8)$ : group $A$ (control, ventilation + saline), group $B$ (1.5 minimum alveolar concentration (MAC) sevoflurane + saline), group C (1.5 MAC sevoflurane + LPS), group D (1.0 MAC sevoflurane + LPS), group E (0.5 MAC sevoflurane + LPS) and group $F$ (ventilation + LPS). The mechanical ventilation and sevoflurane pre-treatment were all performed for $30 \mathrm{~min}$ long. The overall volume was identical in every group. ALI model was established by femoral vein injection with $5 \mathrm{mg} / \mathrm{kg}$ LPS to rats (Jeyaseelan and Chu, 2004). Mean arterial pressure (MAP), PH and arterial blood gas index $\left(\mathrm{PaO}_{2} / \mathrm{FiO}_{2}\right)$ were both measured and recorded at four time points TO (before sevoflurane injection), T1(after 30 min of sevoflurane injection), T2(after $2 \mathrm{~h}$ of sevoflurane injection), T3(after $6 \mathrm{~h}$ of sevoflurane injection) via Datex anaesthetic agent monitor. Sevoflurane, delivered to gas admixture (oxygen) at a concentration of 0.5 MAC, 1.0 MAC and 1.5 MAC via a calibrated vaporizer was administered via an endotracheal tube for $30 \mathrm{~min}$ and the inspired oxygen and sevoflurane concentration were also maintained and monitored constantly by Datex anaesthetic agent monitor. The rectal temperature of all the rats was controlled to 37 to $38^{\circ} \mathrm{C}$ by incandescent bulb heating.

HO-1 expression in lung tissues of LPS-induced ALI with sevoflurane pre-treatment

The surgical method in all rats was the same as earlier mentioned. These rats were also randomly divided into six groups $(n=8)$ : Group A (control, 10\% DMSO + ventilation + saline), Group B (ZnPP + ventilation + saline), group C (10\% DMSO + 1.0 MAC sevoflurane + saline), Group D (10\% DMSO + 1.0 MAC sevoflurane + LPS), group E (ZnPP + 1.0 MAC sevoflurane + LPS) and Group F (10\% DMSO + ventilation + LPS). The DMSO and ZnPP treatment were performed for $10 \mathrm{~min}$, but the mechanical ventilation and sevoflurane pre-treatment were all performed for $30 \mathrm{~min}$ long. The overall volume was identical in every group.

\section{Detection assay}

After $6 \mathrm{~h}$ of drug treatment or saline, all the rats were killed by exsanguination and sample of left lung tissue was remained to assay the activity of MPO and $\mathrm{HO}-1$, the mRNA and protein expression level of ICAM-1, CINC-1 and HO-1 by RT-PCR and Western blot. Right upper lobe was dyed with hematoxylin and eosin (HE) stain to observe the pathological changes but the right middle lobe was used to measure dry/wet ratio (W/D).

\section{Statistical analysis}

All data were analyzed by SPSS 13.0 and the results were measured by average \pm standard deviation $\left(\bar{x}_{ \pm s}\right.$. One-way
ANOVA was used for comparisons between the groups where appropriate. Post hoc comparisons were performed using LSD test or Dunnett's T3 test. $\mathrm{P}<0.05$ was considered as statistically significant.

\section{RESULTS}

The effect of sevoflurane pre-treatment with different concentrations on LPS-induced ALI

\author{
The changes of MAP, $\mathrm{PH}$ and $\mathrm{PaO}_{2} / \mathrm{FiO}_{2}$ in every \\ group
}

The changes of MAP, $\mathrm{PH}$ and $\mathrm{PaO}_{2} / \mathrm{FiO}_{2}$ were all monitored by Datex anaesthetic agent monitor in different time, and the analysis results was shown in Table 1.

\section{The pathological changes, pathomorphological scores, W/D ratio and MPO activity}

In group $A$ and $B$, the alveoli structure was normal with clean alveolar spaces, no inflammatory cell infiltration and no alveolar wall thickening. But in LPS-induced Groups C, D, E and F, we could obviously observe diffuse pulmonary edema in different extent, capillarectasia, hyperaemia, leukopedesis and bleeding, especially in Group F (Figure 1). The results of pathomorphological scores, W/D ratio and MPO activity were shown in Table 2.

\section{mRNA and protein expression level of ICAM-1and CINC}

The mRNA expression level of every group was analyzed with RT-PCR, using GAPDH as an internal standard (Figures $2 \mathrm{~A}$ and $3 \mathrm{~A}$ ). The protein expression level of every group was detected with Western blot, using $\beta$ actin as an internal standard (Figures $2 \mathrm{~B}$ and $3 \mathrm{~B}$ ). The results of statistical analysis were showed in Figures 2C and $3 \mathrm{C}$.

\section{HO-1 expression in lung tissues of LPS-induced ALI rats with sevoflurane pre-treatment}

The pathomorphological scores, W/D and MPO
activity

The results of pathomorphological scores, W/D and MPO activity were showed in Table 3 .

\section{Activity of HO-1 in every group}

The activity of HO-1 was evaluated by traditional method. The results are shown in Table 4. 
Table 1. The changes in MAP, $\mathrm{PH}$ and $\mathrm{PaO}_{2} / \mathrm{FiO}_{2}$ in every group $(\bar{x} \pm \mathrm{s})$.

\begin{tabular}{|c|c|c|c|c|c|c|c|}
\hline Group & & $A(n=8)$ & $B(n=8)$ & $C(n=8)$ & $D(n=8)$ & $E(n=8)$ & $F(n=8)$ \\
\hline \multirow{4}{*}{$\mathrm{MAP}(\mathrm{mmHg})$} & TO & $84.6 \pm 10.1$ & $88.9 \pm 10.4$ & $86.8 \pm 9.1$ & $89.1 \pm 5.8$ & $84.8 \pm 6.1$ & $86.8 \pm 9.4$ \\
\hline & $\mathrm{T} 1$ & $81.8 \pm 7.9$ & $68.9 \pm 4.9^{\# \star}$ & $70.0 \pm 7.6^{\# *}$ & $75.0 \pm 6.4 \#$ & $79.4 \pm 6.1^{\# *}$ & $81.0 \pm 7.5 \#^{\star}$ \\
\hline & $\mathrm{T} 2$ & $83.0 \pm 7.4$ & $81.6 \pm 6.4^{\&}$ & $59.6 \pm 6.8^{\# \& *}$ & $61.6 \pm 7.2^{\# \& *}$ & $62.1 \pm 6.5^{\# \& *}$ & $58.5 \pm 6.1^{\# \& *}$ \\
\hline & T3 & $82.4 \pm 7.7$ & $81.0 \pm 5.6^{\# \&}$ & $65.5 \pm 5.9^{\# \star}$ & $67.1 \pm 6.1^{\# \&_{*}}$ & $66.6 \pm 5.8^{\# \& *}$ & $63.0 \pm 4.9^{\# \&_{*}}$ \\
\hline \multirow{4}{*}{$\mathrm{pH}$} & T0 & $7.41 \pm 0.07$ & $7.41 \pm 0.05$ & $7.43 \pm 0.08$ & $7.42 \pm 0.08$ & $7.41 \pm 0.05$ & $7.38 \pm 0.11$ \\
\hline & $\mathrm{T} 1$ & $7.41 \pm 0.07$ & $7.37 \pm .14$ & $7.35 \pm 0.10$ & $7.40 \pm 0.07$ & $7.37 \pm 0.10$ & $7.33 \pm 0.12$ \\
\hline & $\mathrm{T} 2$ & $7.41 \pm 0.10$ & $7.37 \pm 0.09$ & $7.21 \pm 0.05^{\# \&_{*}}$ & $7.20 \pm 0.07^{\# \&_{*}}$ & $7.20 \pm 0.07^{\# \&_{*}}$ & $7.19 \pm 0.07^{\# \&_{*}}$ \\
\hline & T3 & $7.37 \pm 0.09$ & $7.37 \pm 0.10$ & $7.24 \pm 0.08^{\# \& *}$ & $7.21 \pm 0.07^{\# \& *}$ & $7.19 \pm 0.09^{\# \varepsilon_{*}}$ & $7.20 \pm 0.08^{\# \&_{*}}$ \\
\hline \multirow{4}{*}{$\begin{array}{l}\mathrm{PaO} 2 / \mathrm{FiO} 2 \\
(\mathrm{mmHg})\end{array}$} & TO & $424.5 \pm 21.9$ & $419.1 \pm 30.8$ & $422.5 \pm 27.9$ & $417.8 \pm 29.0$ & $430.1 \pm 28.0$ & $440.9 \pm 27.8$ \\
\hline & $\mathrm{T} 1$ & $418.1 \pm 26.7$ & $409.6 \pm 22.8$ & $424.0 \pm 30.7$ & $419.4 \pm 32.0$ & $412.8 \pm 31.2$ & $423.5 \pm 24.2$ \\
\hline & $\mathrm{T} 2$ & $426.6 \pm 23.4$ & $411.3 \pm 21.7$ & $313.5 \pm 11.2^{\# \& *}$ & $309.5 \pm 13.5^{\# \& *}$ & $315.8 \pm 9.6^{\# \& *}$ & $310.4 \pm 11.4^{\# \& *}$ \\
\hline & T3 & $428.9 \pm 26.4$ & $413.9 \pm 28.4$ & $330.3 \pm 28.2^{\# \varepsilon_{*}}$ & $324.6 \pm 22.4^{\# \varepsilon_{*}}$ & $321.5 \pm 20.9^{\# \& *}$ & $314.3 \pm 28.4^{\# \& *}$ \\
\hline
\end{tabular}

Comparison within groups: Compare with $\mathrm{T} 0{ }^{\#} \mathrm{P}<0.05$ and compare with $\mathrm{T} 1{ }^{\&} \mathrm{P}<0.05$. Comparison between groups: Compare with Group $\mathrm{A}$ ${ }^{*} \mathrm{P}<0.05$; compare with Group $\mathrm{B} \triangle \mathrm{P}<0.05$; compare with Group $\mathrm{C}{ }^{*} \mathrm{P}<0.05$.
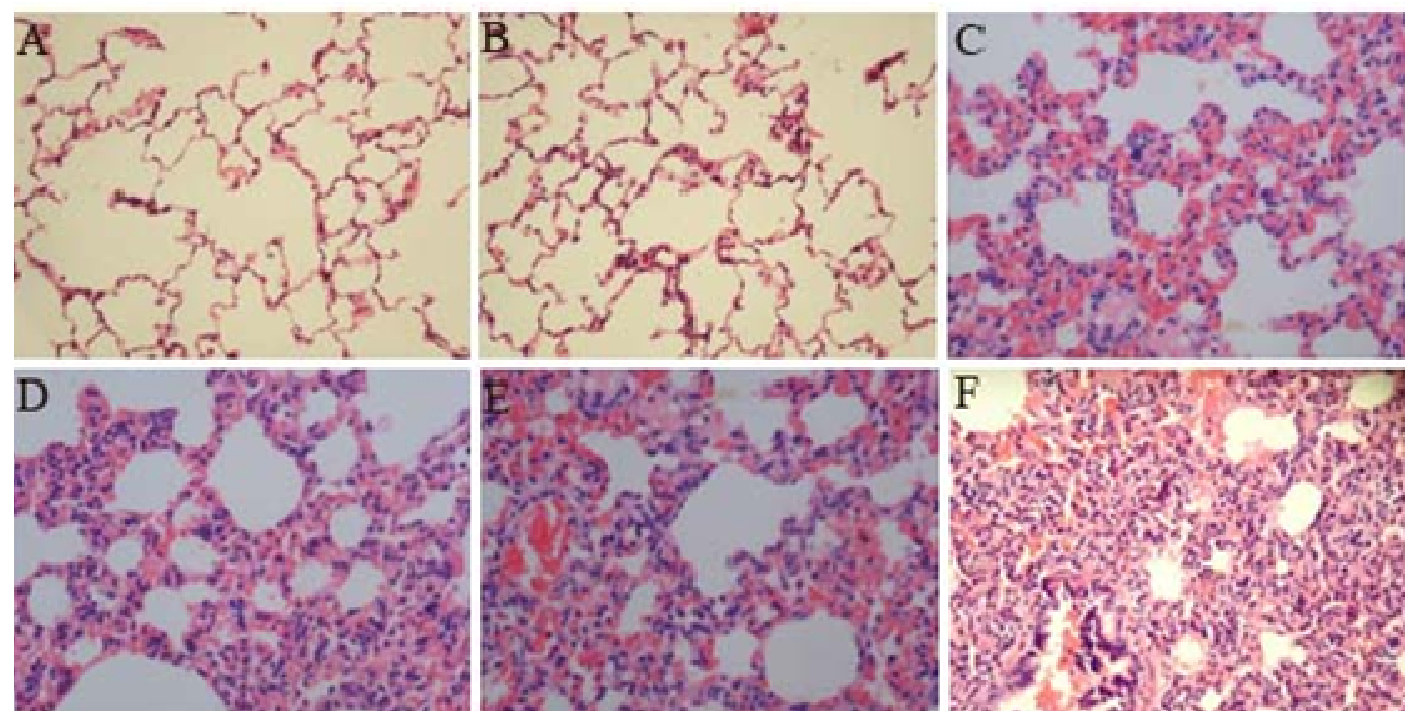

Figure 1. The pathological changes of lung tissue in $A L I$ with different treatment $A, B, C, D, E$ and $F$ indicated each group.

Table 2. Comparison between different group in W/D, pathomorphological scores and the activity of MPO ( $\bar{x} \pm s)$.

\begin{tabular}{lccc}
\hline Group & W/D ratio & MPO activity (U/gprot) & Pathomorphological scores \\
\hline$A(n=8)$ & $3.61 \pm 0.54$ & $5.19 \pm 0.54$ & $1.63 \pm 1.41$ \\
$B(n=8)$ & $3.54 \pm 0.58$ & $5.06 \pm 0.48$ & $2.88 \pm 1.81$ \\
C $(n=8)$ & $4.96 \pm 0.56^{*}$ & $6.60 \pm 0.77^{\star \bullet} \Delta$ & $10.13 \pm 1.81^{\star} \Delta$ \\
$D(n=8)$ & $4.28 \pm 0.63^{*} \Delta$ & $6.56 \pm 0.70^{\star} \Delta_{\Delta}$ & $9.9 \pm 1.25^{\star} \Delta$ \\
$E(n=8)$ & $5.01 \pm 0.71^{*}$ & $7.31 \pm 0.77^{\star} \Delta$ & $11.50 \pm 1.0^{\star \star} \Delta$ \\
$F(n=8)$ & $5.22 \pm 0.81^{*}$ & $8.01 \pm 0.80^{*}$ & $13.88 \pm 1.13^{\star}$ \\
\hline
\end{tabular}

Compare with Group A *P $<0.05$; compare with Group D * $P<0.05$; compare with Group $E{ }^{*} \mathrm{P}<0.05$, and compare with Group $F$ $\triangle \mathrm{P}<0.05$. 


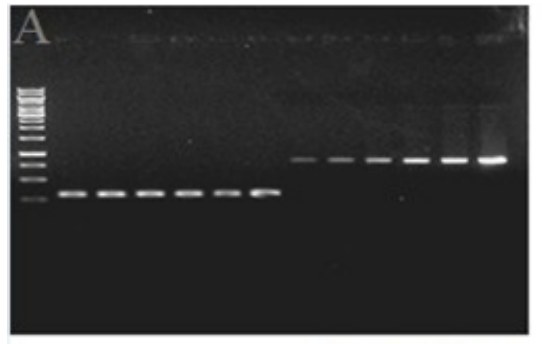

A B C D E F
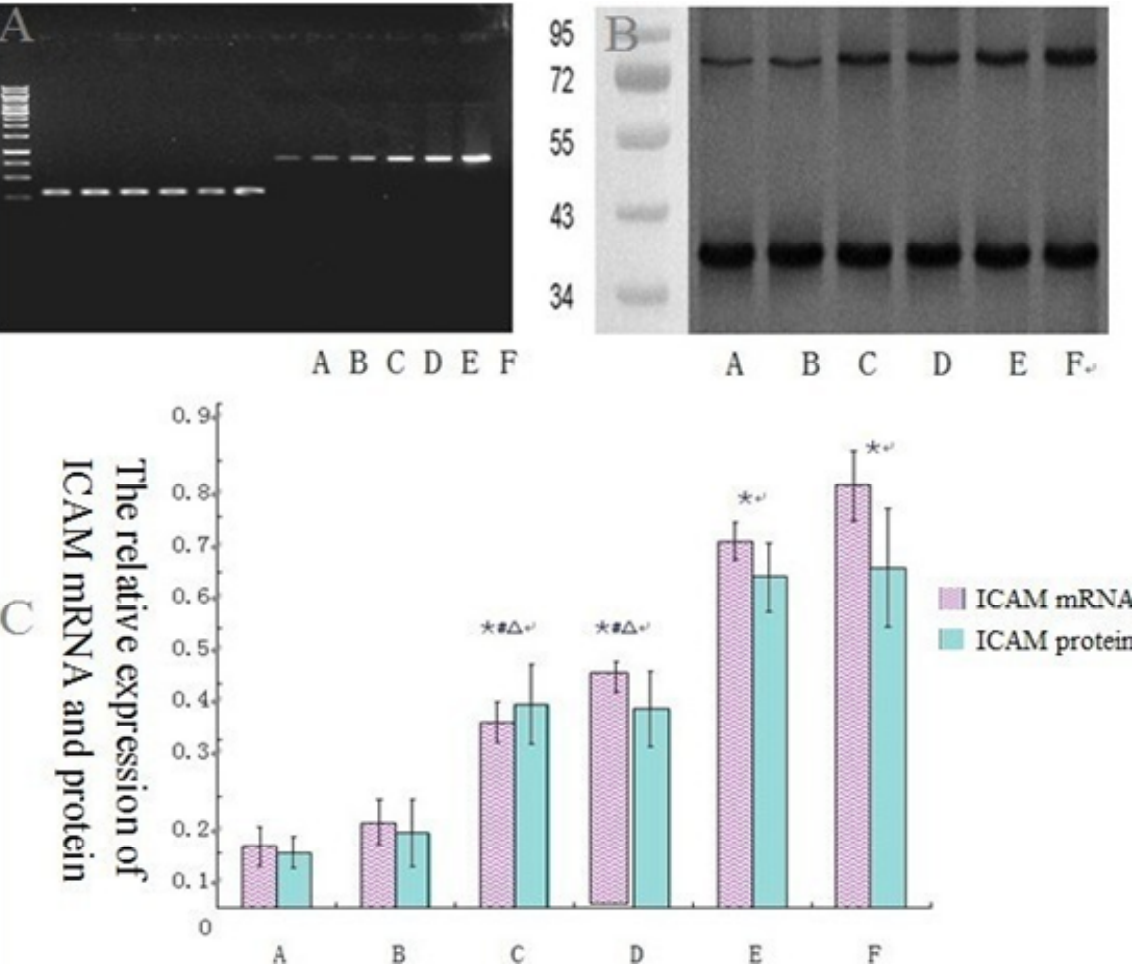

Figure 2. The mRNA and protein expression level of ICAM-1 in every group. A: The mRNA expression level of ICAM-1; B: The protein expression level of ICAM-1; C: The result of statistical analysis (compare with Group $A^{*} P<0.05$, compare with Group $E^{\#} P<0.05$ and compare with Group $\mathrm{F} \triangle \mathrm{P}<0.05)$.

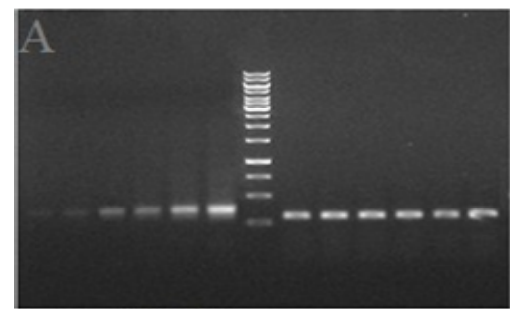

A B C D E F.
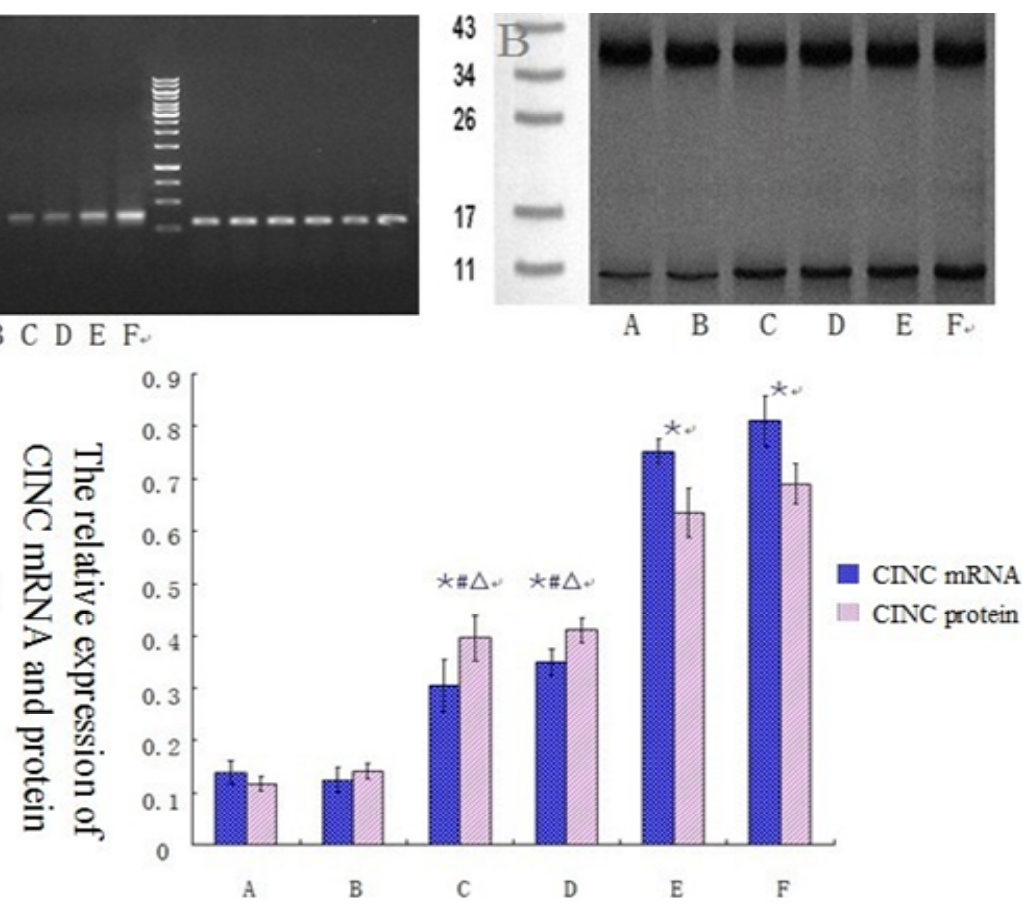

Figure 3. The mRNA and protein expression level of CINC-1 in every group. A: The mRNA expression level of CINC-1; B: The protein expression level of CINC-1and C, the result of statistical analysis (compare with Group $A^{*} P<0.05$, compare with Group $E^{\#} P<0.05$ and compare with Group $F \triangle P<0.05$ ). 
Table 3. Comparison between different group in W/D, pathomorphological scores and the activity of MPO $(\bar{x} \pm s)$.

\begin{tabular}{lccc}
\hline Group & W/D ratio & MPO activity (U/gprot) & $\begin{array}{c}\text { Pathomorphological } \\
\text { scores }\end{array}$ \\
\hline$A(n=8)$ & $3.61 \pm 0.54$ & $5.19 \pm 0.54$ & $1.63 \pm 1.41$ \\
$B(n=8)$ & $3.50 \pm 0.64$ & $5.37 \pm 0.63$ & $2.0 \pm 1.60$ \\
$C(n=8)$ & $3.50 \pm 0.67$ & $5.12 \pm 0.76$ & $2.75 \pm 2.12$ \\
$D(n=8)$ & $4.28 \pm 0.63^{\star}$ & $6.56 \pm 0.70^{\star}$ & $9.88 \pm 1.25^{\star}$ \\
$E(n=8)$ & $5.35 \pm 0.66^{\star \star}$ & $9.24 \pm 1.11^{\star \star}$ & $14.0 \pm 1.07^{\star \star}$ \\
$F(n=8)$ & $5.22 \pm 0.81^{\star \star}$ & $8.01 \pm 0.80^{\star \star}$ & $13.88 \pm 1.13^{\star \star}$ \\
\hline
\end{tabular}

Compare with Group $A{ }^{*} P<0.05$, compare with Group $D{ }^{*} P<0.05$ and compare with Group $E{ }^{*} P<0.05$.

Table 4. The comparison of HO-1 activity between every group $(\bar{x} \pm s)$.

\begin{tabular}{|c|c|c|c|c|c|c|}
\hline Group & $A$ & B & C & D & $E$ & $\mathbf{F}$ \\
\hline $\begin{array}{l}\text { HO-1 activity } \\
\left(\mathrm{nmol} \cdot \mathrm{g}^{-1} \text { prot } \cdot \mathrm{h}^{-1}\right)\end{array}$ & $166.5 \pm 51.3$ & $181.8 \pm 79.0$ & $172.6 \pm 62.1$ & $578.1 \pm 92.0^{*}$ & $218.8 \pm 67.7^{\bullet}$ & $484.9 \pm 88.6^{\star \bullet \#}$ \\
\hline
\end{tabular}

Compare with Group A*P<0.05, compare with Group $D^{*} P<0.05$ and compare with Group $E^{\#} P<0.05$.

\section{The mRNA and protein expression level of HO-1 in every group}

The mRNA and protein expression level of HO-1 in every group were detected by RT-PCR and Western blot, respectively. The results were showed in Figure 4.

\section{The mRNA and protein expression level of ICAM-1 and CINC}

The mRNA and protein expression level of ICAM-1and CINC in every group were also detected by RT-PCR and Western Blot, respectively. The results were showed in Figures 5 and 6.

\section{DISCUSSION}

LPS endotoxin, as a main component of the cell wall of gram-negative bacteria, is the most commonly used injury agent to induce ALI model (Davidson et al., 2002; Chen et al., 2003; Jeyaseelan and Chu, 2004). Therefore, in this work, the ALI model was established by intravenous injection with $5 \mathrm{mg} / \mathrm{kg}$ LPS to rats. The results indicated that after LPS injection for $6 \mathrm{~h}$, the W/D ratio and MPO activity of lung tissue in Groups C, D, E and $F$ were obviously increasing. And diffuse pulmonary edema in different extent, capillarectasia, hyperaemia, leukopedesis and bleeding were all observed, especially in Group F, which demonstrated that the ALI model was successfully established. In addition, ICAM-1 and CINC-1 were identified up-regulated expression at mRNA and protein level, which demonstrated polymorphonuclear neutrophil (PMN) might accumulate in lung tissue to release inflammatory mediator to cause ALI in agreement with the microscopic observation (Menezes et al., 2005).

Dominik et al., (2007) reported that pre-treatment with $0.5 \mathrm{MAC}$ sevoflurane to alveolar epithelial cells for $30 \mathrm{~min}$ could distinctly alleviate LPS-induced inflammation. Liu et al. (2000) found that the W/D ratio and lactate dehydrogenase activity of lung tissue in 1 MAC sevoflurane plus ischemia-reperfusion (I/R) group were lower significantly than $\mathrm{l} / \mathrm{R}$ group, suggesting that sevoflurane could ease I/R ALI. In this study, we applied three different sevoflurane concentration gradients $(0.5$ MAC, 1.0 MAC and 1.5 MAC) to pre-treat for $30 \mathrm{~min}$. The results showed that compare with group $F$, different concentration sevoflurane, all could induce downregulated expression of CINC-1 and ICAM-1 at mRNA and protein level, MPO activity inhibited, and pathomorphological score decreasing to protect lung. However, there was extent difference in different concentration sevoflurane pre-treatment. 0.5 MAC sevoflurane pre-treatment (Group E) could relieve LPSinduced ALI compared with Group F, but there was no significant difference in the W/D ratio, expression level of CINC-1 and ICAM-1. 1.0 MAC (Group D) and 1.5 sevoflurane (group C) pre-treatment effect was ever more evident and significantly different from group $E$ and $F$, but no significant difference between them. In general, we suppose that sevoflurane pre-treatment could protecLPSinduced ALI effectively, and the optimal sevoflurane 


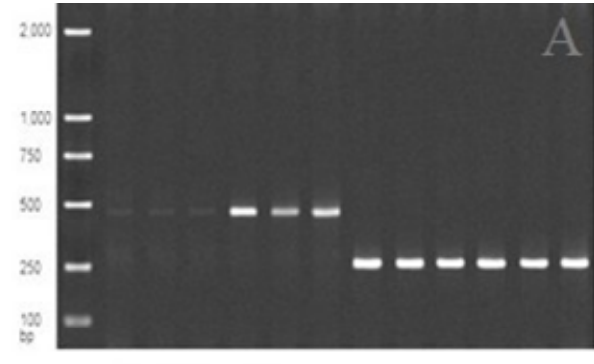

A B C D E F.

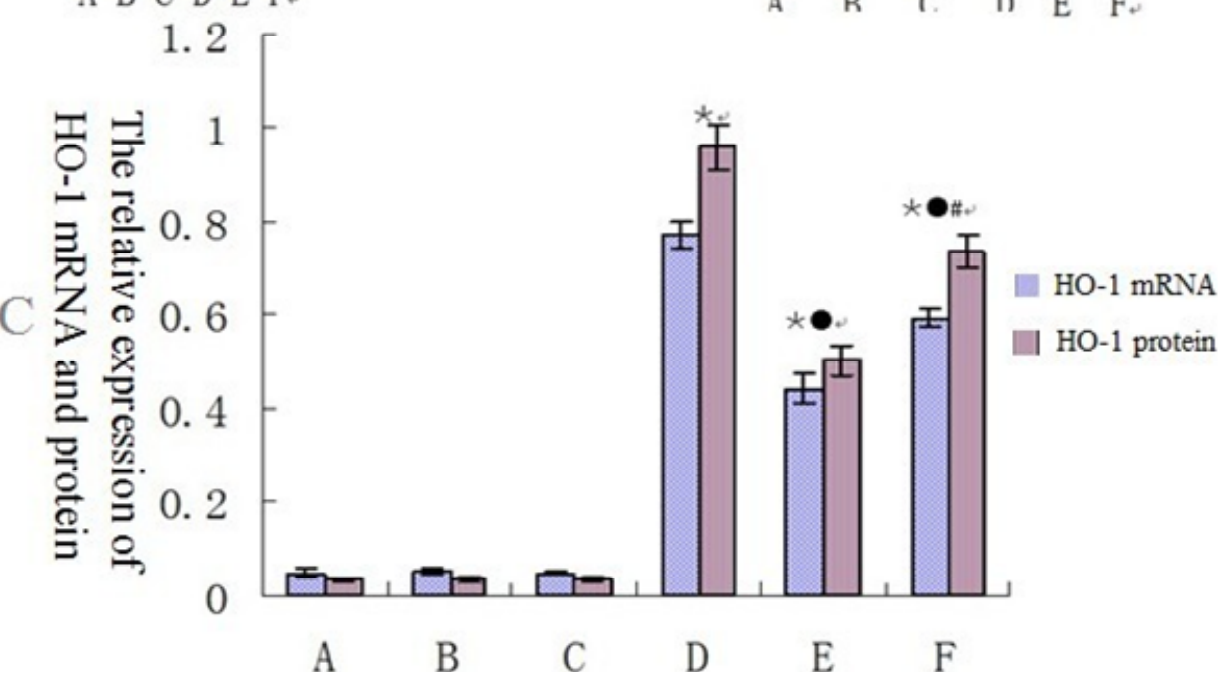

Figure 4. The mRNA and protein expression level of HO-1 in every group. A: The mRNA expression level of $\mathrm{HO}-1, \mathrm{~B}$ : the protein expression level of $\mathrm{HO}-1$ and $\mathrm{C}$ : the result of statistical analysis (compare with Group $A * P<0.05$, compare with Group $D{ }^{*} P<0.05$ and compare with Group E\# ${ }^{\#}<0.05$ ).

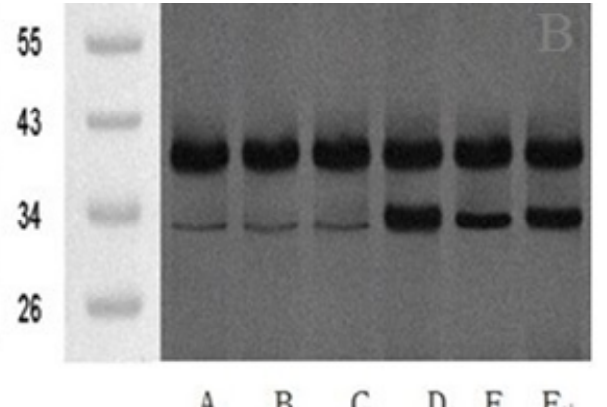




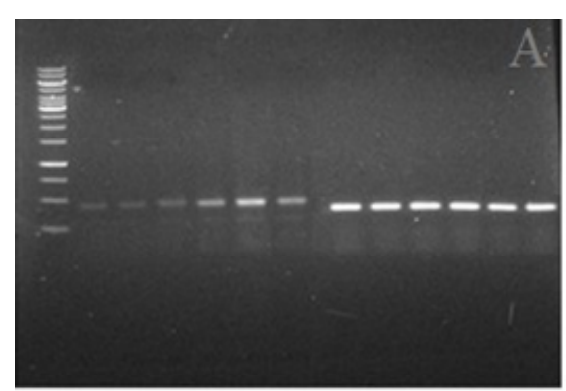

A B C D E F.

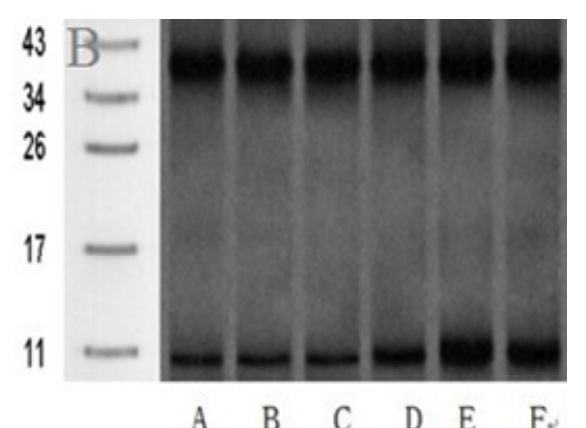

A $\quad$ B $\quad C \quad$ D $E$ F.

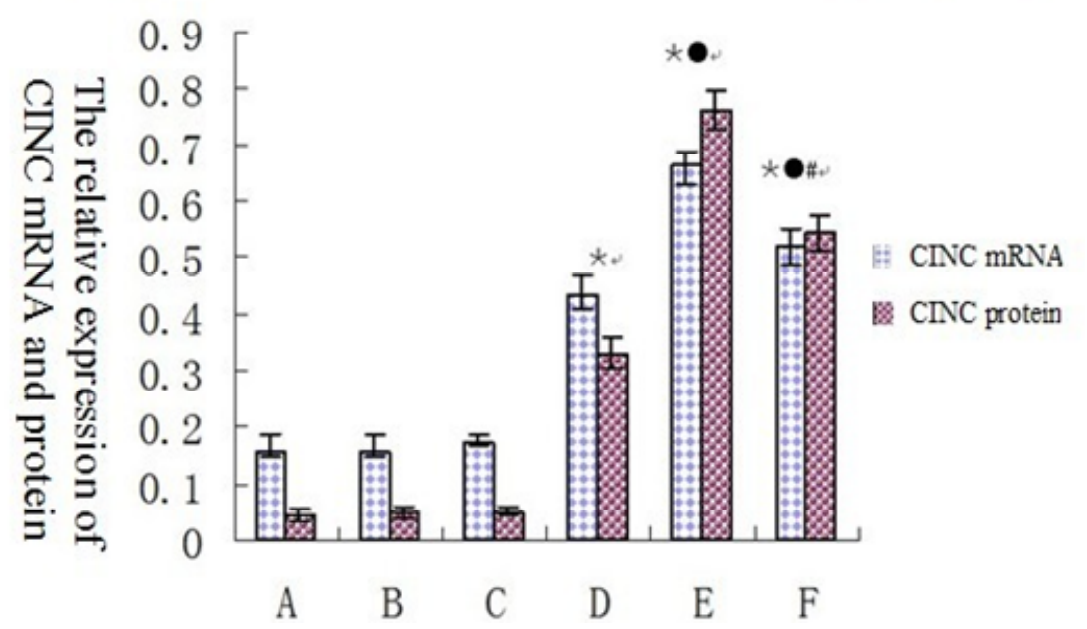

Figure 6. The mRNA and protein expression level of CINC in every group. A: The mRNA expression level of CINC; B: The protein expression level of CINC, and C: The result of statistical analysis (compare with Group A * $P<0.05$, compare with Group $D{ }^{*} P<0.05$ and compare with Group E $\left.{ }^{\#} \mathrm{P}<0.05\right)$.

concentration is $1.0 \mathrm{MAC}$.

$\mathrm{HO}-1$ is the rate limiting enzyme in the degradation of heme and results in the release of equimolar quantities of biliverdin, iron and carbon monoxide (Tenhunen et al., 1968). HO-1 has been demonstrated playing a cytoprotective role in modulating tissue responses to injury in several pathophysiological states, such as $\mathrm{I} / \mathrm{R}$ injury (Tsuchihashi et al., 2005), inflammation (Nath et al., 2001), transplantation (Baan et al., 2004), atherosclerosis (Morsi et al., 2006), cardiovascular diseases (Immenschuh and Schrder, 2006), hypoxiainduced lung injury (Fredenburgh et al., 2007), etc.

Among them, lung $\mathrm{I} / \mathrm{R}$ is an important model of oxidantmediated ALI (Fujita et al., 2001). Isoflurane pretreatment increased hepatic $\mathrm{HO}-1$ mRNA, protein, enzyme activity to protect rat livers from I/R injury, but administration of $\mathrm{HO}-1$ inhibitors abolished the isofluraneinduced protective effects (Schmidt et al., 2007). However, whether sevoflurane could also induce HO-1 regulated expression to inhibit ALI inflammation? We designed six different groups for the test. This study demonstrated that as compare to group $E$ and F, 1.0 MAC sevoflurane per-treatment (group D) could significantly enhance the activity of $\mathrm{HO}-1$, increase the expression of HO-1 at mRNA and protein level, but reduce the pathomorphological score, MPO activity, and the expression of ICAM-1 and CINC. ZnPP, as a substrate of HO-1, weakly induces $\mathrm{HO}-1$ expression but markedly decreases its activity, which explains its usage as potent HO-1 inhibitor (Tsuchihashi et al., 2005). ZnPP was introduced in group $E$ to block up the effect of sevoflurane. The analysis showed that the $\mathrm{HO}-1$ expression was seriously inhibited and ALI exacerbation. Group B was as controlled to exclude ZnPP influence on normal tissue. In conclusion, this work suggested that sevoflurane may take part in ALI protection through inducing $\mathrm{HO}-1$ up-regulated expression.

\section{REFERENCES}

Baan C, Peeters A, Lemos F, Uitterlinden A, Doxiadis I, Claas F, ljzermans J, Roodnat J, Weimar W (2004). "Fundamental Role for HOO) 1 in the Self(C)Protection of Renal Allografts." Am. J. Trans., 4(5): 811-818.

Bhatia M, Brady M Zagorski J, Christmas SE, Campbell F, Neoptolemos JP, Slavin J (2000). "Treatment with neutralising antibody against cytokine induced neutrophil chemoattractant (CINC) protects rats against acute pancreatitis associated lung injury." Gut, 47(6): 838.

Chen ZT, Li SL Cai EQ, Wu WL, Jin JS, Zhu B (2003). "LPS induces 
pulmonary intravascular macrophages producing inflammatory mediators via activating NF-kappaB." J. Cell Biochem., 89(6): 12061214.

Coimbra R, Melbostad H, Loomis W, Porcides RD, Wolf P, Tobar M, Hoyt DB (2006). "LPS-induced acute lung injury is attenuated by phosphodiesterase inhibition: effects on proinflammatory mediators, metalloproteinases, NF-kappaB, and ICAM-1 expression." J. Trauma., 60(1): 115-125.

Davidson KG, Bersten AD, Barr HA, Dowling KD, Nicholas TE, Doyle IR (2002). "Endotoxin induces respiratory failure and increases surfactant turnover and respiration independent of alveolocapillary injury in rats." Am. J. Respir. Crit. Care Med., 165(11): 1516-1525.

Fredenburgh LE, Perrella MA, Mitsialis SA (2007). "The role of heme oxygenase-1 in pulmonary disease." Am. J. Respir. Cell Mole. Biol., 36(2): 158-165.

Fujita T, Toda K, Karimova A, Yan SF, Naka Y, Yet SF, Pinsky DJ (2001). "Paradoxical rescue from ischemic lung injury by inhaled carbon monoxide driven by derepression of fibrinolysis." Nat. Med., 7(5): 598-604.

Immenschuh S, Schrder H (2006). "Heme oxygenase-1 and cardiovascular disease." Histol. Cistopathol., 21(6): 679.

Jeyaseelan S, Chu HW (2004). "Transcriptional profiling of lipopolysaccharide-induced acute lung injury." Infect Immun., 72(12): 7247-7256.

Lee WL, Downey GP (2001). "Neutrophil activation and acute lung injury." Current Opin. Crit. Care, 7(1): 1.

Leikauf GD, McDowell SA, Wesselkamper SC, Hardie WD, Leikauf JE, Korfhagen TR, Prows DR (2002). "Acute Lung Injury." Chest, 121(3 suppl): $70 S-75 S$.

Liu R, Ishibe Y, Ueda M (2000). "Isoflurane-sevoflurane administration before ischemia attenuates ischemia-reperfusion-induced injury in isolated rat lungs." Anesthesiology, 92(3): 833-840.

Menezes SLS, Bozza PT, Neto HC, Laranjeira AP, Negri EM, Capelozzi VL, Zin WA, Rocco PR (2005). "Pulmonary and extrapulmonary acute lung injury: inflammatory and ultrastructural analyses." J. Appl. Physiol., 98(5): 1777-1783.
Morsi WG, Shaker OG, Ismail EF, Ahmed HH, El-Serafi TI, Maklady FA, Abdel-Aziz MT, El-Asmar MF, Atta HM (2006). "HO-1 and VGEF gene expression in human arteries with advanced atherosclerosis." Clin. Biochem., 39(11): 1057-1062.

Nath KA, Vercellotti GM, Grande JP, Miyoshi H, Paya CV, Manivel JC, Haggard JJ, Croatt AJ, Payne WD, Alam J (2001). "Heme proteininduced chronic renal inflammation: Suppressive effect of induced heme oxygenase-1." Kidney Int., 59(1): 106.

Pang QF, Zhou QM, Zeng S, Dou LD, Ji Y, Zeng YM (2008). "Protective effect of heme oxygenase-1 on lung injury induced by erythrocyte instillation in rats." Chin. Med. J. (Engl), 121(17): 1688-1692.

Randhawa R, G Bellingan (2007). "Acute lung injury." Anaesth. Intensive Care Med., 8(11): 477-480.

Schmidt R, Tritschler E, Hoetzel A, Loop T, Humar M, Halverscheid L, Geiger KK, Pannen BH (2007). "Heme oxygenase-1 induction by the clinically used anesthetic isoflurane protects rat livers from ischemia/reperfusion injury." Ann. Surg., 245(6): 931-942.

Suter D, Spahn DR, Blumenthal S, Reyes L, Booy C, Z'graggen BR, Beck-Schimmer B (2007). "The immunomodulatory effect of sevoflurane in endotoxin-injured alveolar epithelial cells." Anesth Analg., 104(3): 638-645.

Tenhunen R, Marver HS, Schmid R (1968). "The enzymatic conversion of heme to bilirubin by microsomal heme oxygenase." Proc. Natl. Acad. Sci. USA, 61(2): 748-755.

Tsuchihashi S, Zhai Y, Fondevila C, Busuttil RW, Kupiec-Weglinski JW (2005). HO-1 upregulation suppresses type 1 IFN pathway in hepatic ischemia/reperfusion injury, Elsevier. 37(4):1677-1678.

Tsuchihashi S, Zhai Y, Fondevila C, Busuttil RW, Kupiec-Weglinski JW (2005). "HO-1 upregulation suppresses type 1 IFN pathway in hepatic ischemia/reperfusion injury." Transplant Proc., 37(4): 1677-1678. 